\title{
What are young people's experiences of an anti-bullying Drama in Education workshop six months' post-participation?
}

There is no agreed operational definition of bullying. Various studies define bullying as a repeated, direct or indirect negative action resulting in harmful behaviours which target an individual over a long period of time (Monks et al, 2009; Modecki et al., 2014; Sinkkonen et al, 2012).

Self-reported, survey responses from 10,020 young people between the ages of 10 and 20 attending secondary schools and colleges across the UK suggest that one in two have experienced some form of bullying with one in ten bullied in the past week (Ditchthelabel.org, 2017). Evidence suggests that there is a strong correlation between bullying and reduced academic attainment (Varghese \& Pistole, 2017; Nodin et al, 2017). More than 16,000 young people were reported absent from school in the UK, 2016, due to bullying and upwards of $50 \%$ of students in higher education have experienced bullying online (Varghese \& Pistole, 2017; Nodin et al, 2017).

Drama is recognized as an important approach in connecting and involving young people, working with complex and sensitive issues of health promotion (Orme, Salmon \& Mages, 2007; Anderson et al., 2012). There is evidence that young people's engagement with the arts can help all participants and even the most vulnerable develop knowledge and skills (Lloyd, 2003; Orme, Salmon \& Mages, 2007).

The purpose of this primary research study was to explore young people's experiences of an anti-bullying Drama in Education workshop. It aims to understand the meanings young people have attributed to their experiences in relation to the workshop using an interpretative study design and to understand if the intervention has influenced participant's knowledge, skills, and behaviours. The research helps to fill the knowledge gap of the mechanisms in which arts and health promotion interventions enhance social and cognitive skills in young people and focuses on the longitudinal impact of drama interventions and their relevance in enhancing longterm skills and knowledge. The research aims to create insight into the essence of 
the phenomena, generating new ideas and modifying existing theories by combining constructivist and interpretivist approaches to explore and reflect the increasing complexities of health promotion and health education in young people.

\section{Forum Theatre and Social Learning Theory}

Forum theatre defined by Boal (2000) is a platform which enables people to change their perceptions and view of the world. Boal (2000) suggests that observation of a piece of theatre enables the audience to participate actively in examining the problem and seeking a resolution. By assuming the role of a 'spectactor' participants can rehearse real-life situations in a safe, simulated environment. Social learning theory infers that people learn through observational modelling of others' attitudes, behaviours, and outcomes (Bandura, 1971). These two theories complimented each other to elicit participants' own cognitive and emotional responses to problem solve a bullying situation. The workshop aimed to empower 30 young people in a Brownie group with resilience, knowledge, and skills to cope with bullying in the future, focusing on improving relationships and social awareness, through empathy, social competence, tolerance and support of a bullied friend.

\section{Intervention}

The intervention was a movement piece depicting a bullying scenario between two friends. The piece is set to music and uses non-verbal communication. The movement piece is shown twice, during the replay audience members are invited to stop the action and make recommendations to change the situation or take the place of the victim. The structure of the Drama in Education workshop is detailed in table 1.

\section{Methods}

Focus groups were conducted consisting of five, 6 to 10-year-old, self-selected girls, who all participated in the workshop 6 months earlier, representing one third of the total group. This size group helped to generate discussion from a variety of perspectives but was still small enough not to become too disorderly or fragmented (Holloway \& Galvin, 2017). Familiarity with each other and the researcher from the workshop and the preliminary meeting helped the group to relax at the beginning. The environment was familiar to the participants, comfortable and away from any 
distractions. The group is in an affluent community and all participants have similar socio-demographics with little or no difference in age, gender, family type or parent's education. However, it is recognized that this is too small group to compare local statistics or demonstrate any significant variability or findings by ethnic or cultural background. Eight participants were white British. Ethic or cultural background did not demonstrate any significant variability or findings and the sample group composition appeared representative of the local community.

\section{Data collection}

Data was collected through recordings of the focus groups. Data from participants were anonymized and only the researcher could match names and identities. Safe guarding procedures were in place. A protocol for procedure and notification of the authorities in the event of disclosure of a safe guarding issue was agreed with the group leader prior to the session. A confidentiality agreement was signed by the videographer.

To enhance the oral data collected from the focus groups, all participants were invited to create a drawing of one key message they took away from the workshop. Previous studies show that the use of diverse methods with younger children provides richer more valuable information (Clark, Kjorholt \& Moss, 2005; Einarsdottir, 2007). Children's drawings can provide a carefully considered visual insight into young people's views through non-verbal expression but these may be limited depending on the time available. (Clark, Kjorholt and Moss, 2005; Einarsdottir, 2007). The children's narratives around their drawings were transcribed on the back of each picture by the researcher.

\section{Ethical considerations}

The United Nations Convention on the rights of a child (Unicef, 2018) suggests that children and young people have the right to be consulted around issues that have a direct or indirect impact or effect on their lives. Children are strong, adept and knowledgeable experts of their own lives (Einasdottir, 2007). However, they are deemed as vulnerable persons in society, therefore additional ethical considerations were required for this study. Written permissions were received for this study from 
Girl Guiding UK and the Brownie unit leader and ethical approval was granted by The University of West London ethics committee UWL/REC/CMHT-344. Prior to the focus group, parents were asked for written consent for their child's participation in the study and the use of video recording. Assent forms were completed by the children at the preliminary session with the researcher one week before the focus group where they were given an opportunity to ask any questions. The purpose of the assent form was to reinforce the child's right to refuse or dissent from the focus groups even if consent had already been given by the parents (Phelan \& Kinsella, 2012).

Attached to the consent and assent forms were two information leaflets - one for parents and one for the children - outlining what the research involved and contained both words and pictures. The leaflet identified any potential risks associated with the research - for example disclosure of sensitive issues or evoked emotions - were highlighted to both parents and children. Assent was confirmed again at the beginning of the focus group.

The group leader was always present during the focus groups acting as a guardian in case any individuals showed signs of distress or discomfort (Nutbrown, 2010; Phelan \& Kinsella, 2012). All verbal and non-verbal communication, gestures or actions which might have been contrary to the consent/assent given were observed by the researcher throughout (Einarsdottir, 2007). No participant left or was removed from the focus group at any time because they appeared stressed or concerned.

Reducing harm was an important consideration for this research project. Although an emphasis was made on the participants right to withdraw and assent was provided at the beginning of the workshop it is debatable given the Brownie and societal hierarchies, whether any of the children would have openly or directly refused to be involved. However, some participants chose only to communicate by shaking or nodding their heads and did not contribute to the overall discussions. These noncommunications were noted and transcribed and the participants were not pushed to give a verbal response.

\section{Data Analysis}


Data were collected from the focus groups using interpretation and observational analysis. Data analysis included two phases of coding, general content coding and specific content coding. In the first phase the videos were watched for overall content and identification of major categories. A coding template using NVivo software program was developed around the major categories. Each focus group was transcribed and coded separately. The second phase was to identify major, relevant and overarching themes across both groups. The categories were used to create a hierarchical index system and conceptual framework hierarchy to analyse for reoccurring themes, dominant themes and subsume minor themes (Maltby et al., 2014). Coding templates for each group were reviewed for overarching relevant themes.

Data were triangulated across three sampling strategies; spoken information gathered from the focus groups; interpretation of non-verbal communications from analysis of the video recording and the descriptive narratives from the drawn pictures. In the beginning, themes appeared to be directly linked to the questions asked for example behavioural change and relating to the characters. The sub themes around self-efficacy, understanding around the concept of bullying and emotional and cognitive developments were drawn through interpretation of the data.

\section{Results}

The three themes that emerged from the focus groups regarding the young people's perception of the workshop were: 1) Personal relevance and the ability to relate to the characters; 2) Self-efficacy to make behavioural changes; 3) Recall of the workshop and key messages.

The results show the features of the anti-bullying workshop that the children found effective, their response to the workshop and the longitudinal impact.

\section{Recall of the workshop}

All the children in the focus groups could easily recall the main theme of the theatre piece and workshop and demonstrated considerable powers of observation and recall. All could describe the characters and story, and most could describe or 
demonstrate key movements from the theatre piece that they remembered six months later. Within in this age group, there were significant differences in how the children articulated what they recalled from the workshop. For most, it was the visual images of the theatre piece that were prominent.

'I keep thinking of the other lady when she was pushing you and you fell to the floor'

Others could recall easily what was discussed and how some of the discussions had a greater impact on them.

I liked the bit when we were discussing what we could do and about how we could make a friendship again.'

Some of the children found the negative images easier to recall as it triggered a strong emotion and resonated with personal experiences. Most of the children could recall strong images such as the scene when the victim is pushed to the ground by the bully.

'I remember that bit strongly because I remember being bullied and it's very hurtful. I remember that you tried to make friends but she did not want to and you tried and tried and then you gave up. And then she felt a bit sorry and then she tried. And afterwards, there was tenderness and then she would lash out again.'

'When I saw, you get hurt. Because I don't like seeing people get hurt.'

A few of the children could compare this bullying workshop to previous workshops around the same subject. They commented that they had greater recall of the key message about supporting your friends from this workshop compared to other nontheatre workshops.

\section{Key messages/ Drawings}

The children were asked to draw a key message from the workshop at the end of the interviews. The children's narratives around the drawings and were transcribed on the back of each picture.

Some of the children drew pictures of the strongest image they could recall from the theatre piece. 
'When she pushed you over and you got back up'

Others drew their own experiences and how these had related to the workshop. Most of the children drew something that would help others in the future such as stop bullying posters with catchy slogans or templates others could use. The messages on the posters included 'get help,' 'Tell a teacher,' 'Stand up for yourself,' 'Help others who are being bullied,' and 'don't start being a bully.'

\section{Behavioural change}

The anti-bullying workshop involved genuine participation in the form of the forum theatre component, the group discussions and in the role play 'rehearsal' section. One of the main objectives of the workshop was to encourage new behaviours and self-efficacy to deal with bullying situations. Most children commented that they felt they had dealt with a situation differently because of the workshop:

'I went back to my old friend and I told her all about the workshop and how we could make friends again and she listened to me and we became friends.'

Others felt their overall perception of others had been influenced and that they had changed the way in which they interacted and communicated with peers demonstrating a higher level of understanding around inclusivity.

'I changed the way I felt about friends. I started to encourage them and said to my other friend every game must be open for everyone.'

Although these children may not have developed these new behaviours solely from participating in the workshop, the focus groups revealed that their attention has been focused towards understanding bullying behaviours and their involvement in managing these situations.

'Whenever I see somebody not involved in a game that is my age and I sometimes play with I go over and say to them do you want to play. Because, if you are alone it's easier to get bullied.' 
Additionally, some children reported that they were more likely to support the bullied friend following the workshop and get support from peers or an adult when necessary.

'People who are my friends I have helped them when people have been mean to them, and I have tried to be their friend.'

Some indicated that they understand the issues and implications of bullying on a deeper level and that the concept of 'bully-victims' whereby situations in which the bullied resort to bullying behaviours was recognizable.

'Some people they think that if they get bullied they think that they should bully.'

Often the children commented on a renewed sense of self-efficacy where they felt able to manage otherwise previously challenging situations. With self-efficacy comes a possibility of linking the recalled information from the workshop into real-life situations.

'I got bullied by my friend and I thought about what you said and I said why don't we just forget about it and she said OK. So, I stopped it there.'

Overall, the children spoke positively about the workshop. They could remember key messages from the workshop and demonstrate how they had applied these to situations in their own lives. Most of the children could recall visual images from the theatre piece, particularly those which resonated and evoked strong emotions. The children demonstrated a sense of empowerment and self-efficacy following the workshop with many giving examples of how they had helped others. Most of the children spoke freely about their experiences and concluded that the workshop was both enjoyable and informative.

\section{Discussion}

Given the high rate of bullying amongst young people and the adverse consequences associated with bullying-related behaviours, developing effective tools and interventions to support young people to manage these situations is an important public health goal. Creating interventions which are engaging, current and culturally relevant can be challenging (Joronen et al., 2011). Previous research 
indicates that longitudinal assessment of these interventions is limited (Joronen et al., 2011). The findings from this study suggest that Drama in Education creates a positive impact on young people enhancing self-efficacy, self-awareness, empathy and social competence which contributes to sustainable behavioural change.

\section{Personal relevance}

The personal relevance and association with the characters emerged as a main factor and a key behavioural motivator. Discussions around similar scenarios and lived experiences were central. Many of the focus group drew a parallel between the theatre piece and an event or events in their own lives, allowing participants to view the story from their own health perspective and to review their risk or susceptibility to bullying situations. The participants demonstrated renewed personal insight and emotional intelligence, showing the capacity to recognize their own emotions in bullying situations and the emotions of others. Emotional intelligence was demonstrated by the children discerning between different feelings, labelling them and describing changes in their perceptions (Goleman, 2010).

'It made me feel a bit sad because sometimes I don't realise on the inside but I just tend to say something and it upsets somebody.'

The findings are consistent with other health promotion initiatives which demonstrate the effectiveness of participant engagement (Orme, Salmon \& Mages, 2007; Haines, Neumark-Sztainer \& Morris, 2008; Lieberman et al., 2011). Studies found that a message perceived as highly personally relevant responds to children's own circumstances, understanding, moral values and has been shown to have a direct link with social behaviour (Feldman \& Ruble, 1988; Van Reijmersdala et al., 2016). Children are prone to low levels of information processing and heuristic cues can help influence changes (Van Reijmersdala et al., 2016). Through drama in education, the participants were able to search for meaning to bear witness to their own lives. Forum theatre is a mechanism to explore socially conscious issues through theatre and supports the development of social change (Boal, 2000). The implementation of this technique showed that the children were able to develop skills in critical thinking, empathy and social engagement (Pataki \& Mackenzie, 2012), countering the traditionally held perception that children are passive recipients of knowledge (Bury, Popple \& Barker, 1998). 
The immersive approach used in the anti-bullying Drama in Education workshop whereby the person is transported into the narrative enables the story experience to become a personal experience evoking an emotional response to the characters. Most of the children commented that they did not like it when the victim was hurt and this made them feel sad.

'It made feel like in between of sad and like sorry because she was hurting you.'

As a learning process, transportation into the narrative reflects a shift or a transfer in both cognitive and emotional domains (Nicklas et al., 2017). The major dimensions of these include cognitive attention to the story, emotional involvement, articulation of feelings and existence of mental imagery (Nicklas et al., 2017). Transportation compliments both behavioural change (Prochaska \& Velicer, 1997) and social cognitive theories (Bandura, 1976) in terms of eliciting a strong response which prompts cues to action based on learnt social skills. This study highlighted the importance of reinforcing knowledge with children not just learning from an external source but by allowing them to process, interpret, make sense of the situation and remember the key messages.

\section{Key messages}

The findings of the study revealed that the children were able to recall certain images and key messages from the workshop particularly those that made them feel uncomfortable or concerned for the character. The children described aspects of the drama with which they could draw affinity and felt that they learnt from each other how best to manage situations through the group discussions. During the workshop, the participants were asked to join in, stand up to the bully and help the victim. They commented that they remembered this strongly as a tool for future situations particularly with regards to peer support.

'You told us that you should go and find a friend because bullies don't like seeing them being bullied and you could get stronger.'

They also indicated that they felt that the key message about supporting friends was stronger in the workshop compared to other non-theatre anti-bullying workshops they had attended. The evidence from the focus groups suggested that the children had 
developed deeper, longer lasting learning by challenging their own moral grounding through a social and cultural lens (Bandura, 1971).

'It helped me at the end when you made up. And there was a way of making up.'

Although the children stated that they found the workshop helpful in managing bullying situations, a number commented that they could not quite remember what was said in the workshop but they remembered the images from the theatre piece strongly and could apply these to their own situations.

Previous studies which have focused on persuasive messages for health communications, albeit online, had demonstrated little positive attention from children (Van Reijmersdala et al., 2016). Affect-based sensory learning which activates strong thoughts and feelings of like or dislike is more likely to stimulate thought processes, evoke cognitive and emotional responses and create changes in attitudes. Using theatre as a transportation mode, the narrative mirrored scenarios that the children could identify with from their own experiences (Dill-Shackleford et al., 2015). This contrasts with the persuasive approach and is congruent with similar studies which suggest that active participation in anti-bullying interventions reduces victimization (Flygare, Gill \& Johansson, 2013).

'I just got bullied once and now it stopped and I think it has helped it to stop.'

Similar situations, problems or events can trigger learning transactions to stimulate a response and lead to behavioural change (Kenny \& Wirth, 2009).

\section{Behavioural change}

The children were able to describe times in which they had changed their approach to a bullying situation and reflected on the improved outcomes from this. New insights were highlighted by descriptions of the bullies they had encountered since the workshop. Knowledge of different types of bullying and the concept of 'bullyvictims' proved high amongst most of the children.

'Somebody they think that if they get bullied they think that they should bully.'

Behavioural change was measured using a recall method (Howard, 2011) and the Transtheoretical Model of Health Behaviour change from the perspective of any new 
approaches, developments and insights that the children had gained (Prochaska \& Velicer, 1997). The workshop sought to empower the children when facing bullying situations and contribute to changes in their areas of control and influence (Prochaska \& Velicer, 1997).

'I changed the way I felt about friends. I started to encourage them more.'

These findings support the use of Drama in Education as an anti-bullying intervention over previous anti-bullying non-theatre interventions. Non-theatre antibullying messages with older groups elicited student responses that limited the effectiveness of the intervention and ranged from denial, non-participation and attempts to discredit or defy the messages (Cunningham et al., 2016). Occasionally, the reverse happened whereby bullying occurred immediately after or as a direct response to bullying interventions (Cunningham et al., 2016). The evidence from this study of the anti-bullying Drama in Education workshop, however, indicated that participants felt empowered to stand up to bullying.

Self-efficacy is a motivation-related construct found to have a positive impact on the health behaviours of young people (Hass \& Hartmann, 2018). Previous studies show that simulated participation and interaction within peer groups were very effective particularly with managing emotional responses and developing understanding (Haines et al., 2008; Chung, Monday \& Perry, 2017). This type of engagement allows the participants to experience alternative scenarios representative of real life. The opportunity to rehearse life leads to deeper interpretation, empathy and articulates a vision for social change amongst young people (Boal, 2000).

I thought that was how the world might be. I think it taught me that everyone should stop it.'

In contrast to previous anti-bullying studies which have primarily focused on interventions based on the social cognitive principles such as modelling for behavioural change, this study demonstrates that the workshop also developed social skills and personal reflection which can lead to systemic changes towards managing bullying. The children appeared more confident about bullying and how to deal with bullies. They talked freely about their own experiences and demonstrated evidence of self-reflection. Most notably, the children showed deeper emotional 
understanding and considered themselves to be stronger when supporting others and themselves. Participants learn more effectively by taking control of their learning and creating meaning from observations and stimuli (Vygotsky, 1978).

'I went up to my friends and said how are you feeling today?'

'I liked the bit when people kept sticking up for you because that when you get bullied and I like helping people when they get bullied.'

Children learn by doing and actively participating in the world around them (Piaget, 1965). The children commented that they enjoyed the active participation in the workshop and that it gave them confidence to understand situations from both the bully and the victim's perspectives to work out solutions.

'When we got to like do the acting. Because it shows like if you are bullying someone it shows how mean you are being.'

Running one workshop in a Brownie group is not sufficient in itself to generate sustainable behaviour changes but it is critical to commence the initial engagement, motivational and supportive environment necessary for children to take ownership of the key messages and initiate changes (Lloyd, Wyatt \& Creanor, 2012). Sufficient contemplation, preparation and action towards health behaviour changes ensures a more secure platform for maintained and sustainable change (Prochaska \& Velicer, 1997). This reinforces the notion that change occurs in young people when they identify their own strengths and adaptively confront the challenges to experience positive outcomes (Geldard, 2014). This was also measured in the focus group through the narrative around the children's drawings.

\section{Drawings}

The children ended the focus group with drawings, one to summarise what they felt about the drama workshop and one to show something that made them happy.

The use of creative arts and children's drawings within an interview process provides children with the time and opportunity to access their internal, sensory cues to organize their thoughts and perceptions before they share them (Driessnack and Furukawa, 2011). Drawings are recognized as a child-sensitive, culturally appropriate approach which uniquely elicits information from children that creates 
new insights and understandings to empower the shyer and less articulate (Driessnack and Furukawa 2011). Children appear to be able to illustrate their emotions and feelings within drawings more easily than with verbal articulation (Angell, Alexander \& Hunt, 2014).

Self-expression is one of the basic needs of a child and the use of art to transfer thoughts and feelings can be more effective than the spoken language (Kocer, 2012). The use of these drawings helped to construct a more vivid picture of the events recalled by the children and how they have processed these. This can lead them to a deeper scientific understanding consistent with the social learning theory (Bandura, 1971).

\section{Study limitations}

The small sample size precluded analysis of themes across diverse socio-economic groups, gender and ethical groups. The term bullying was defined in a broad sense focusing on any form of repeated, unwarranted negative behaviour which results in harm towards an individual or group (Monks et al, 2009; Modecki et al., 2014; Sinkkonen et al, 2012). This definition was reinforced at the beginning of the focus groups, but some examples given through the discussion did not meet the criteria and therefore were excluded from the write-up.

The study used measures of self-reporting which may be subject to social desirability, recall bias, response bias and inaccurate reporting. It is important to note that analysis of the themes and sub-themes for this research have been coded by the researcher and may not be what the child intended to express.A larger RCT would provide broader generalizable results and stronger evidence of the effectiveness of the intervention towards changing perceptions and behaviour in young people.

\section{Conclusion}

Drama in Education is often undervalued and underfinanced despite proven benefits of health promotion, particularly, in young people. This research confirms the need for future studies around the use of theatre as a leading pedagogy in this field and a 
rationale for future investment in community interventions to promote individual and societal change.

\section{References}

Monks, C., Smith, P., Naylor, P., Barter, C., Ireland, J. and Coyne, I. (2009). Bullying in different contexts: Commonalities, differences and the role of theory. Aggression and Violent Behavior, 14(2), pp.146-156.

Modecki, K., Minchin, J., Harbaugh, A., Guerra, N. and Runions, K. (2014). Bullying Prevalence Across Contexts: A Meta-analysis Measuring Cyber and Traditional Bullying. Journal of Adolescent Health, 55(5), pp.602-611.

Sinkkonen, H., Puhakka, H. and Meriläinen, M. (2012). Bullying at a university: students' experiences of bullying. Studies in Higher Education, 39(1), pp.153-165.

Ditchthelabel. (2017). Ditchthelabel The Annual Bullying Survey 2017. [online] Available at: http://ttps://www.ditchthelabel.org/research-papers/the-annual-bullying-survey-2017/ [Accessed 30 Nov. 2017].

Varghese, M. and Pistole, M. (2017). College Student Cyberbullying: Self-Esteem, Depression, Loneliness, and Attachment. Journal of College Counseling, 20(1), pp.7-21.

Nodin, N., Peel, A., Tyler, A. and Rivers, I. (2017). The RaRE research report: LGB\&T mental health - risk and resilience explored. The RaRE research report: LGB\&T mental health - risk and resilience explored. PACEHealth.

Orme, J., Salmon, D. and Mages, L. (2007). Project Jump: Young People's Perspectives on a Sexual Health Drama Project for Hard to Reach Young People. Children \& Society, 21(5), pp.352-364.

Anderson, L., Goodman, R., Holtzman, D., Posner, S. and Northridge, M. (2012). Aging in the United States: Opportunities and Challenges for Public Health. American Journal of Public Health, 102(3), pp.393-395. 
Lloyd, G., Stead, J. and Kendrick, A. (2003). Joined-up Approaches to Prevent School Exclusion. Emotional \& Behavioural Difficulties, 8(1), pp.77-91.

Boal, A. (2000). Theatre of the Oppressed. Theatre Communications Group.

Holloway, I. and Galvin, K. (2017). Qualitative research in nursing and healthcare. 4th ed. Chichester: Wiley \& Sons.

Bandura, A. (1971). Psychological modeling. Chicago: Aldine·Atherton.

Clark, A., Kjorholt, A. and Moss, P. (2005). Beyond listening: children's perspectives on early childhood services. 1st ed. Bristol: Policy Press, pp.490-505.

Einarsdóttir, J. (2007). Research with children: methodological and ethical challenges. European Early Childhood Education Research Journal, 15(2), pp.197-211.

Phelan, S. and Kinsella, E. (2012). Picture This ... Safety, Dignity, and Voice_Ethical Research With Children. Qualitative Inquiry, 19(2), pp.81-90.

Nutbrown, C. (2010). Naked by the Pool? Blurring the Image? Ethical Issues in the Portrayal of Young Children in Arts-Based Educational Research. Qualitative Inquiry, 17(1), pp.3-14.

Maltby, J., Williams, G., McGarry, J. and Day, L. (2014). Research Methods for Nursing and Healthcare. Hoboken: Taylor and Francis.

Joronen, K., Konu, A., Rankin, H. and Astedt-Kurki, P. (2011). An evaluation of a drama program to enhance social relationships and anti-bullying at elementary school: a controlled study. Health Promotion International, 27(1), pp.5-14.

Goleman, D. (2010). Working with emotional intelligence. [Concordville, Pa.]: Soundview Executive Book Summaries.

Haines, J., Neumark-Sztainer, D. and Morris, B. (2008). Theater as a Behavior Change Strategy: Qualitative Findings from a School-Based Intervention. Eating Disorders, 16(3), pp.241-254. 
Lieberman, L., Berlin, C., Palen, L. and Ashley, O. (2011). A Theater-Based Approach to Primary Prevention of Sexual Behavior for Early Adolescents. The Journal of Early Adolescence, 32(5), pp.730-753.

Feldman, N. and Ruble, D. (1988). The Effect of Personal Relevance on Psychological Inference: A Developmental Analysis. Child Development, 59(5), p.1339.

van Reijmersdal, E., Rozendaal, E., Smink, N., van Noort, G. and Buijzen, M. (2016). Processes and effects of targeted online advertising among children. International Journal of Advertising, 36(3), pp.396-414.

Pataki, S. and Mackenzie, S. (2012). Modeling Social Activism and Teaching About Violence Against Women Through Theatre Education. Psychology of Women Quarterly, 36(4), pp.500-503.

Bury, A., Popple, K. and Barker, J. (1998). You've Got to Think Really Hard: children making sense of the aims and content of Theatre in Health Education. Research in Drama Education: The Journal of Applied Theatre and Performance, 3(1), pp.13-27.

Nicklas, T., Lopez, S., Liu, Y., Saab, R. and Reiher, R. (2017). Motivational theater to increase consumption of vegetable dishes by preschool children. International Journal of Behavioral Nutrition and Physical Activity, 14(1).

Prochaska, J. and Velicer, W. (1997). The Transtheoretical Model of Health Behavior Change. American Journal of Health Promotion, 12(1), pp.38-48.

Bandura, A. (1976). Social learning theory. Englewood Cliffs, NY: Prentice-Hall.

Dill-Shackleford, K., Green, M., Scharrer, E., Wetterer, C. and Shackleford, L. (2015). Setting the Stage for Social Change: Using Live Theater to Dispel Myths About Intimate Partner Violence. Journal of Health Communication, 20(8), pp.969-976.

Flygare, E., Gill, P. and Johansson, B. (2013). Lessons From a Concurrent Evaluation of Eight Antibullying Programs Used in Sweden. American Journal of Evaluation, 34(2), pp.170-189. 
Kenny, R. and Wirth, J. (2009). Implementing Participatory, Constructivist Learning Experiences Through Best Practice in Live Interactive Preformance. The Journal of Effective Teaching, 9(1), pp.34-47.

Cunningham, C., Mapp, C., Rimas, H., Cunningham, L., Mielko, S., Vaillancourt, T. and Marcus, M. (2016). What limits the effectiveness of antibullying programs? A thematic analysis of the perspective of students. Psychology of Violence, 6(4), pp.596-606.

Haß, J. and Hartmann, M. (2018). What determines the fruit and vegetables intake of primary school children? - An analysis of personal and social determinants. Appetite, 120, pp.82-91.

Chung, H., Monday, A. and Perry, A. (2017). Promoting the Well-being of Urban Youth through Drama-based Peer Education. American Journal of Health Behavior, 41(6), pp.728739.

Vygotski1̌, L. and Cole, M. (1978). Mind in society. Cambridge: Harvard University Press.

Piaget, J. (1965). The moral judgement of the child. 1st ed. New York: Free Press.

Lloyd, J., Wyatt, K. and Creanor, S. (2012). Behavioural and weight status outcomes from an exploratory trial of the Healthy Lifestyles Programme (HeLP): a novel school-based obesity prevention programme. BMJ Open, 2(3), p.e000390.

Geldard, K. (2014). Practical interventions for young people at risk. 2nd ed. London: British Library Cataloguing in Publication data.

Driessnack, M. and Furukawa, R. (2011). Arts-based data collection techniques used in child research. Journal for Specialists in Pediatric Nursing, 17(1), pp.3-9.

Kocer, H. (2012). The Evaluation of the Art Activities Applied in Preschool Education Programmes in Terms of Self-Expression Opportunity Given to Child. Procedia - Social and Behavioral Sciences, 51, pp.289-295. 
Angell, C., Alexander, J. and Hunt, J. (2014). 'Draw, write and tell': A literature review and methodological development on the 'draw and write' research method. Journal of Early Childhood Research, 13(1), pp.17-28. 